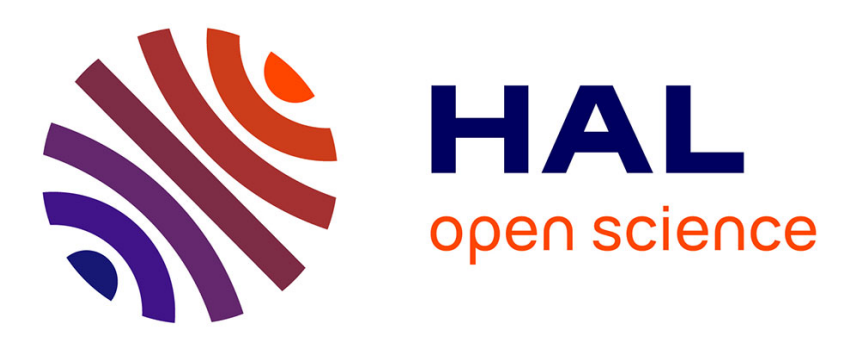

\title{
Hematocrit and hematocrit viscosity ratio during exercise in athletes: Even closer to predicted optimal values?
}

\author{
Jean-Frédéric Brun, Emmanuelle Varlet-Marie, E. Raynaud
}

\section{To cite this version:}

Jean-Frédéric Brun, Emmanuelle Varlet-Marie, E. Raynaud. Hematocrit and hematocrit viscosity ratio during exercise in athletes: Even closer to predicted optimal values?. Clinical Hemorheology and Microcirculation, 2017, 64 (4), pp.777 - 787. 10.3233/CH-168012 . hal-01803689

\section{HAL Id: hal-01803689 \\ https://hal.umontpellier.fr/hal-01803689}

Submitted on 9 Mar 2020

HAL is a multi-disciplinary open access archive for the deposit and dissemination of scientific research documents, whether they are published or not. The documents may come from teaching and research institutions in France or abroad, or from public or private research centers.
L'archive ouverte pluridisciplinaire HAL, est destinée au dépôt et à la diffusion de documents scientifiques de niveau recherche, publiés ou non, émanant des établissements d'enseignement et de recherche français ou étrangers, des laboratoires publics ou privés. 


\title{
Hematocrit and hematocrit viscosity ratio during exercise in athletes: Even closer to predicted optimal values?
}

\author{
Jean-Frédéric Brun ${ }^{\mathrm{a}, *}$, Emmanuelle Varlet-Marie ${ }^{\mathrm{b}, \mathrm{c}}$ and Eric Raynaud de Mauverger ${ }^{\mathrm{a}}$ \\ ${ }^{\mathrm{a}}$ UMR CNRS 9214-Inserm U1046 «Physiopathologie \& Médecine Expérimentale du Cour et des \\ Muscles - PHYMEDEXP », Unité d'Explorations Métaboliques (CERAMM), Université de \\ Montpellier, Département de Physiologie Clinique, Hôpital Lapeyronie CHU Montpellier, France \\ ${ }^{\mathrm{b}}$ Institut des Biomolécules Max Mousseron (IBMM) UMR CNRS 5247, Université de Montpellier, \\ Ecole Nationale Supérieure de Chimie de Montpellier, France \\ ${ }^{\mathrm{c}}$ Laboratoire de Biophysique \& Bio-Analyses, Faculté de Pharmacie, Université de Montpellier, France
}

\begin{abstract}
The hemorheological theory of optimal hematocrit suggests that the best value of hematocrit (hct) should be that which results in the highest value of the hematocrit/viscosity $(\mathrm{h} / \eta)$ ratio. Trained athletes compared to sedentary subjects have a lower hct, but a higher $\mathrm{h} / \eta$, and endurance training reduces the discrepancy between the actual hct and the «ideal» hct that can be predicted with a theoretical curve of $h / \eta v s$ hct constructed with Quemada's model. In this study we investigated what becomes this homeostasis of $\mathrm{h} / \eta$ and hot during acute exercise in 19 athletes performing a 25 min exercise test. $\mathrm{VO}_{2 \max }$ is negatively correlated to resting hct and positively correlated to discrepancy between actual and ideal resting hct which is correlated to the maximal rise in hct during exercise. Predicted and actual values of the $\mathrm{h} / \eta$ were fairly correlated $(r=0.970$ $p<0.001$ ) but the actual value was lower at rest and this discrepancy vanished at 25 min exercise. Exercise-induced decrease in discrepancy between actual and theoretical $\mathrm{h} / \eta$ was negatively correlated with the score of overtraining. All these findings suggest that $\mathrm{h} / \eta$ is a regulated parameter and that its model-predicted «optimal» values yield a «theoretical optimal» hct which is close to the actual value and even closer when athletes are well trained. In addition, acute exercise sets $\mathrm{h} / \eta$ closer from its predicted ideal value and this adaptation is impaired when athletes quote elevated scores on the overtraining questionnaire.
\end{abstract}

Keywords: Blood viscosity, hematocrit, exercise, erythrocyte deformability, hematocrit/viscosity ratio

\section{List of symbols}

het hematocrit

RBC red blood cell

SEM standard error on the mean

\section{Introduction}

Hematocrit is most often acutely increased by exercise and lowered by exercise training, so that it has been repeatedly reported to be negatively correlated to aerobic working capacity [4].

*Corresponding author: Jean-Frédéric Brun, UMR CNRS 9214-Inserm U1046 « Physiopathologie \& Médecine Expérimentale du Cœur et des Muscles - PHYMEDEXP », Unité d'Explorations Métaboliques (CERAMM), Université de Montpellier, Département de Physiologie Clinique, Hôpital Lapeyronie CHU Montpellier, France. Tel.: +33 467338284; Fax: +33 467338986; E-mail: j-brun@chu-montpellier.fr. 
However, the issue of hct in exercise physiology is much more complex since a moderate increase in hct in physiological conditions induces vasodilation and thus improves blood flow [20], while a small decrease (approximately $-10 \%$ ) of het induced by isovolumic hemodilution with homologous plasma in hamsters leads to an increase in blood pressure [21]. In addition there are training protocols that do not decrease het and rather increase it [16].

The idea that there is an optimal het is an old one [26] but it has recently gained an impressive support with studies on transgenic mice [25] showing that exercise performance describes a bell-shaped curve as a function of hct. Interestingly, this bell-shaped curve has been hypothesized on a theoretical basis since more than 30 years by hemorheologists $[6,27]$ and is explained by the biphasic effect of het on $\mathrm{h} / \eta$. Below optimal hct, any increase in hct increases $\mathrm{h} / \eta$ and thus (theoretically) $\mathrm{O}_{2}$ supply to tissues, but above this optimal value, any further increase has the opposite effect and decreases $h / \eta$ and $\mathrm{O}_{2}$ supply.

It has become clear over the last years that $\mathrm{h} / \eta$ is not only a theoretical concept but a clinically relevant parameter that can predict vascular events [28] and is associated to tissue ischemia [29].

Therefore it is interesting to try to predict the optimal hct with hemorheological models that take into account this concept of $h / \eta$, and to compare its value to the actual one in various physiological and pathological conditions. An attractive procedure for this is to use the very classical Quemada's equation to reconstruct from actual viscosity factors the curve of $h / \eta$ and to detect the hct corresponding to the top of this curve.

In a previous study we reported that endurance training tends to reduce the discrepancy between the actual hct and the «ideal» hct that can be predicted with a theoretical curve of $h / \eta v s$ hct constructed with Quemada's model using actual viscosity parameters. We hypothesized that training involved «viscoregulatory» mechanisms that actually aim at maintaining an optimal $\mathrm{h} / \mathrm{\eta}$ and that optimal het is only a reflect of this homeostasis of $h / \eta$.

A raise in het is the most classical hemorheological effect of exercise. It is due to fluid shifts and splenocontraction. To what extent this rise in het during exercise modifies the homeostasis of $h / \eta$ is not known. It can be hypothesized that resting het in athletes is set at a level which allows to cope with exercise-induced increase in hct, but there is until now no clear evidence of this.

Therefore, in this study we investigated in another sample of athletes with various levels of aerobic capacity whether this discrepancy between the predicted "optimal" values of $h / \eta$ and hct and the actual ones were related to fitness and what they became when hot increases during exercise.

\section{Subjects and methods}

\subsection{Study subjects}

We studied 19 male recreational and professional athletes (soccer, volleyball; age: 17-33 years; \%fat: 6-12\%; $\mathrm{VO}_{2 \max }: 41-61 \mathrm{ml} / \mathrm{min} / \mathrm{kg}$ ). Characteristics of subjects are given on Table $1 . \mathrm{VO}_{2 \max }$ ranged between $77 \%$ and $180 \%$ of the predicted theoretical value, so that this sample displays a wide rage of aerobic capacities.

Exercise test was done according to the protocol of Raynaud et al. [18] which is standardized for the exploration of metabolic and hormonal adaptation to exercise. This test consists of a progressive increase over $10 \mathrm{~min}$ in order to reach $85 \%$ of the maximal theoretical heart rate which is maintained over $15 \mathrm{~min}$. In this test heart rate was monitored but not oxygen consumption. Blood samples are drawn at 10 and 25 min of exercise.

$\mathrm{VO}_{2 \max }$ was evaluated during this test according to Astrand's nomogram [1, 2], assuming the relationship between oxygen consumption $\left(\mathrm{VO}_{2}\right)$ in $1 / \mathrm{min}$ and power output $(\mathrm{P})$ in watts established by 
Clinical characteristics of the study subjects (mean + SEM)

\begin{tabular}{lr}
\hline Age (years) & $21.74 \pm 1.08$ \\
Weight $(\mathrm{kg})$ & $77.96 \pm 1.72$ \\
Height $(\mathrm{cm})$ & $184.34 \pm 2.29$ \\
Body mass index $\left(\mathrm{kg} / \mathrm{m}^{2}\right)$ & $22.96 \pm 0.39$ \\
Fat mass $(\%$ total weight $)$ & $8.94 \pm 0.39$ \\
Overtraining score SFMES & $10.64 \pm 1.61$ \\
$\mathrm{VO}_{2} \max (\mathrm{ml} / \mathrm{min} / \mathrm{kg})$ & $48.54 \pm 2.72$ \\
\hline
\end{tabular}

Astrand and Ryhming $\mathrm{VO}_{2}=0.1+0.938 \mathrm{xP}$ with a correction for age $\mathrm{f}=1.21-\left(9.1 \times 10^{-3} \mathrm{x}\right.$ age $)$. This classical approach developed in physically fit college students has a reported accuracy of approximately $10 \%$, which has been recently confirmed by Cink \& Thomas [7]. It has been recently found to be valid for recreationally active males and females [5]. Note that in untrained sedentary subjects [19] it has been shown to yiel a $26.5 \%$ systematic underestimation of $\mathrm{VO}_{2 \max }$.

The specific questionnaire for detection of overtraining in athletes, developed in France by the French Society of Exercise and Sports Medicine (SFMES), was also employed [3, 12, 15]. This score which is also validated on a modified form in children [30] indicates the heaviness of training and when its score is $>20$ it indicates that an individual is at least on the edge of overtraining [14].

\subsection{Bioelectrical impedance measurements}

Prior to the exercise-test, subjects' body composition was assessed with bioimpedance analysis with a six terminal impedance plethismograph BIACORPUS RX 4000, (SoAGIL DEVELOPPEMENT, 8 avenue Jean-Jaurès 92130 Issy-les-Moulineaux, France) with data analysis with the software BodyComp 8.4. This device measures total resistance of the body to an alternative electric current of $50 \mathrm{kHz}$ [9]. Body fat mass, fat-free mass were calculated in each segment of the body according to manufacturer's database-derived disclosed equations, and total water with published equations using the classical cylindric model and Hanai's mixture theory [10].

\subsection{Hemorheological in vitro measurements}

Blood samples for hemorheological measurements $(7 \mathrm{ml})$ were drawn with potassium EDTA as the anticoagulant in a vacuum tube (Vacutainer). Viscometric measurements were done at very high shear rate $\left(1000 \mathrm{~s}^{-1}\right)$ with a falling ball viscometer (MT 90 Medicatest, F-86280 Saint Benoit). The coefficient of variation of this method ranges between 0.6 and $0.8 \%$. We measured with this device apparent viscosity of whole blood at native het, plasma viscosity, and blood viscosity at corrected het (45\%) according to the equation of Quemada [17].

$$
\eta=\eta_{\mathrm{p}}(1-1 / 2 \mathrm{k} \phi)^{-2}
$$

- where $\phi$ is hematocrit, $\eta_{\mathrm{p}}$ is plasma viscosity, and $\mathrm{k}(\gamma)$ is a shear-dependent parameter quantifying the contribution of erythrocyte rheological properties to whole blood viscosity.

- At the high shear rate used here $\mathrm{k}(\gamma)$ is representative of red cell rigidity (i.e., the lower $\mathrm{k}(\gamma)$ ), the higher is erythrocyte deformability).

With this equation it is possible to standardize $\eta$ for het $45 \%$ after calculating $\mathrm{k}$ :

$$
\mathrm{k}=2 \cdot\left(1-\eta \mathrm{r}^{-0.5}\right) \cdot \phi^{-1}
$$


This value of $k$ is reintroduced in equation (1) with $\phi$ set at 0.45 . Dintenfass's 'Tk' index [6] was also calculated as an index of red cell rigidity.

RBC aggregation was assessed with the Myrenne aggregometer [23] which gives two indices of RBC aggregation: " $\mathrm{M}$ " (aggregation during stasis after shearing at $600 \mathrm{~s}^{-1}$ ) and "M1" (facilitated aggregation at low shear rate after shearing at $600 \mathrm{~s}^{-1}$ ). Hematocrit was measured with microcentrifuge.

\subsection{Prediction of the theoretical optimal hematocrit and hematocrit viscosity ratio}

The curve of theoretical optimal $\mathrm{h} / \eta$ plotted $v s$ hct was reconstructed with Quemada's equation presented above. The equation of $h / \eta$ as a function of $h$ was thus:

$$
\mathrm{h} / \eta=\mathrm{h} /\left[\eta_{\mathrm{p}}(1-1 / 2 \mathrm{k} \phi)^{-2}\right]
$$

The hct corresponding to the top of this curve was considered as the "theoretical optimal hematocrit". The highest value of $h / \eta$ (the top of the curve) was considered as the optimal $h / \eta$.

\subsection{Statistics}

Values are presented as mean \pm standard error of the mean (SEM). Normality of samples was checked with the Kolmogorov-Smirnov test. After verification of normality, we used ANOVA followed by posthoc Student's $t$ test for paired samples. Correlations were assessed with Pearson's procedure (least square fitting). A value of $p<0.05$ was considered as significant.

\section{Results}

The graded $25 \mathrm{~min}$ exercise test was performed with drawings at 0,10 and $25 \mathrm{~min}$, i.e. at $10 \%, 48 \%$ and $76 \% \mathrm{VO}_{2 \max }$. Table 2 shows the main hemorheologic changes during this exercise test.

It can be seen that whole blood viscosity at both native $(p<0.01)$ and corrected hct $(p<0.05)$ increases during exercise, due to a rise in hot $(p<0.02)$ and plasma viscosity $(p<0.02)$ while RBC rigidity is not significantly changed in this study.

Table 2

Hemorheologic changes during exercise. It can be seen that whole blood viscosity at both native and actual hematocrit increase during exercise, due to a rise in hematocrit, plasma viscosity. In this sample changes in RBC rigidity index are not significant

\begin{tabular}{|c|c|c|c|c|}
\hline & Rest & $\begin{array}{l}\text { Time } \\
10 \mathrm{~min}\end{array}$ & $\begin{array}{l}\text { Time } \\
25 \mathrm{~min}\end{array}$ & $\begin{array}{c}\text { Overall comparison } \\
\text { (ANOVA) exercise effect }\end{array}$ \\
\hline Actual het (\%) & $44.63 \pm 0.53$ & $45.97 \pm 0.61$ & $46.05 \pm 0.86$ & $p<0.02$ \\
\hline $\begin{array}{l}\text { Whole blood viscosity at het } \\
\text { corrected } 45 \%(\mathrm{mPa} . \mathrm{s})\end{array}$ & $3.37 \pm 0.10$ & $3.41 \pm 0.10$ & $3.69 \pm 0.21$ & $p<0.05$ \\
\hline $\begin{array}{l}\text { Whole blood viscosity at actual } \\
\text { hct (mPa.s) }\end{array}$ & $3.36 \pm 0.10$ & $3.62 \pm 0.10$ & $3.65 \pm 0.08$ & $p<0.01$ \\
\hline Plasma viscosity (mPa.s) & $1.40 \pm 0.01$ & $1.43 \pm 0.01$ & $1.47 \pm 0.03$ & $p<0.02$ \\
\hline ' $\mathrm{k}$ ' index (Quemada) & $1.58 \pm 0.05$ & $1.63 \pm 0.05$ & $1.60 \pm 0.04$ & NS \\
\hline Theoretical maximal $\mathrm{h} / \eta$ & $13.65 \pm 0.43$ & $12.95 \pm 0.45$ & $12.88 \pm 0.32$ & $p<0.05$ \\
\hline Actual h/ $\eta$ & $13.48 \pm 0.44$ & $12.74 \pm 0.46$ & $12.86 \pm 0.35$ & $p<0.05$ \\
\hline Theoretical optimal het (\%) & $42.89 \pm 1.48$ & $41.33 \pm 1.55$ & $42.58 \pm 1.08$ & NS \\
\hline
\end{tabular}



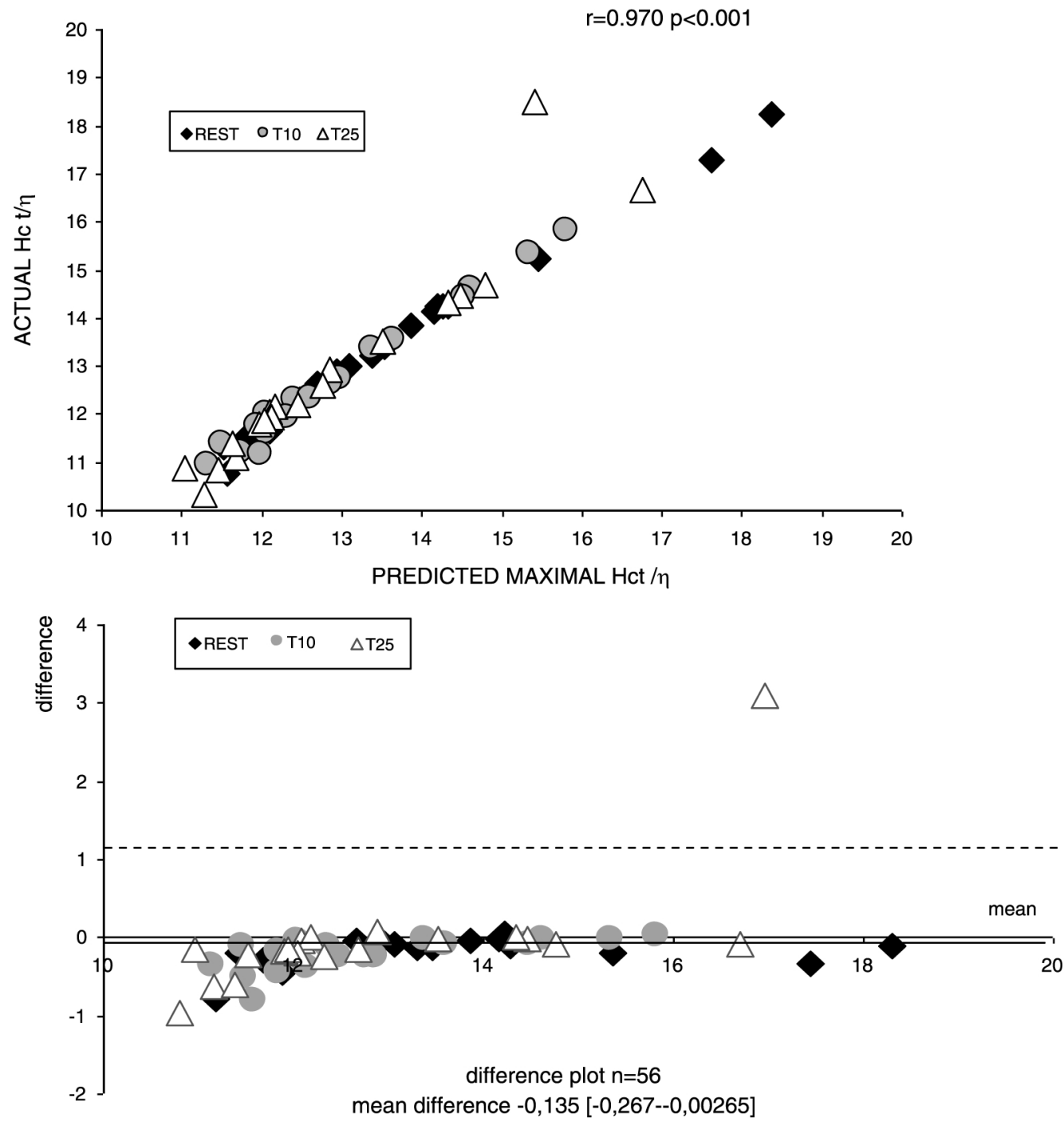

Fig. 1. Upper pannel: Correlation between the $h / \eta$ ratio predicted with the model and the actual $h / \eta$. Lower pannel: BlandAltman plot showing the agreement between the $h / \eta$ ratio predicted with the model and the actual $h / \eta$. On the whole the agreement between theoretical and optimal is very strong. However one point at T25 has a h/ $\eta$ markedly higher than predicted.

Figure 1 shows that here is a fair agreement between theoretical and optimal values of $h / \eta$. Predicted and actual values of the $\mathrm{h} / \eta$ were fairly correlated $(r=0.970, p<0.001)$ but the actual value was slightly lower at rest $(1.26, p<0.01)$ and at 10 min exercise $(-1.68, p<0.001)$ and this discrepancy vanished at 25 min exercise.

However, as seen on Fig. 2, agreement is less close between optimal hat predicted with the model and the actual het.

It can be seen that on the average actual het is slightly higher than the predicted optimal het. Figure 3 shows reconstructed curves of the theoretical optimal $\mathrm{h} / \eta$ plotted $v s$ actual het in the subjects at rest and at exercise, showing that the theoretical optimal $h / \eta$ tends to be higher at rest than during exercise $(p<0.01)$. On Fig. 4 it can be seen that exercise decreases the discrepancy between theoretical and actual $h / \eta$ ratio but increases the discrepancy between theoretical and actual het. 


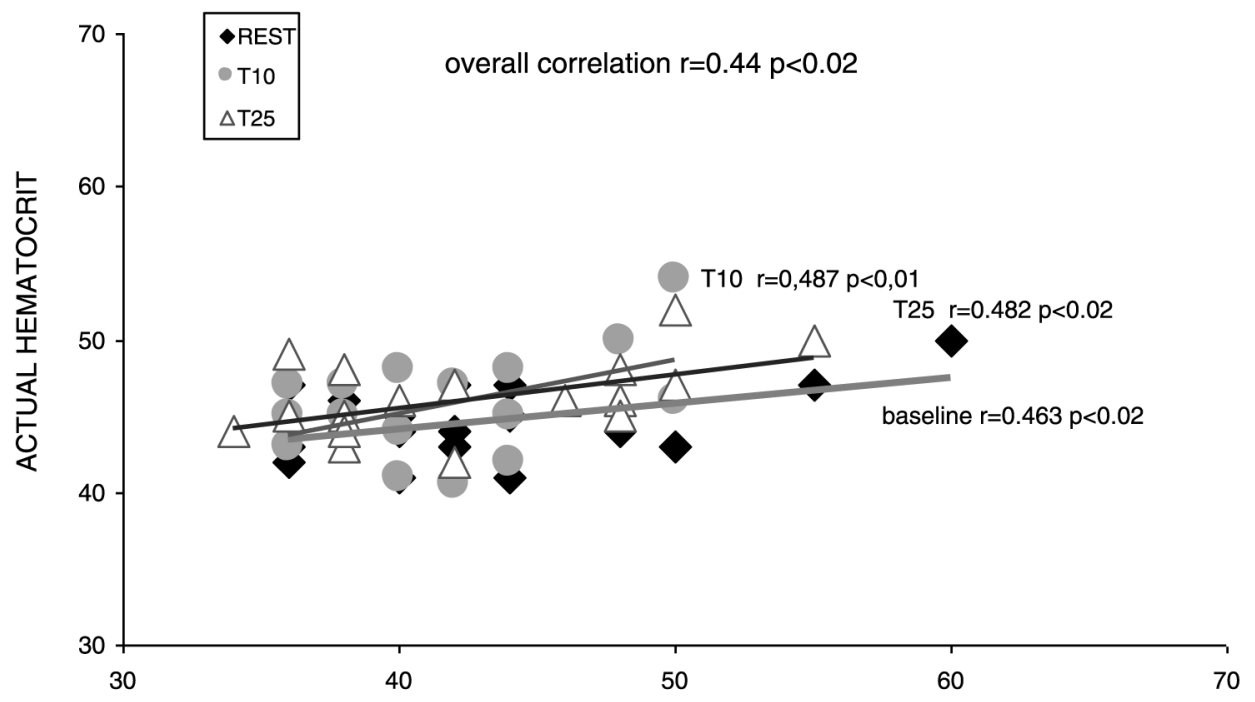

PREDICTED OPTIMAL HEMATOCRIT

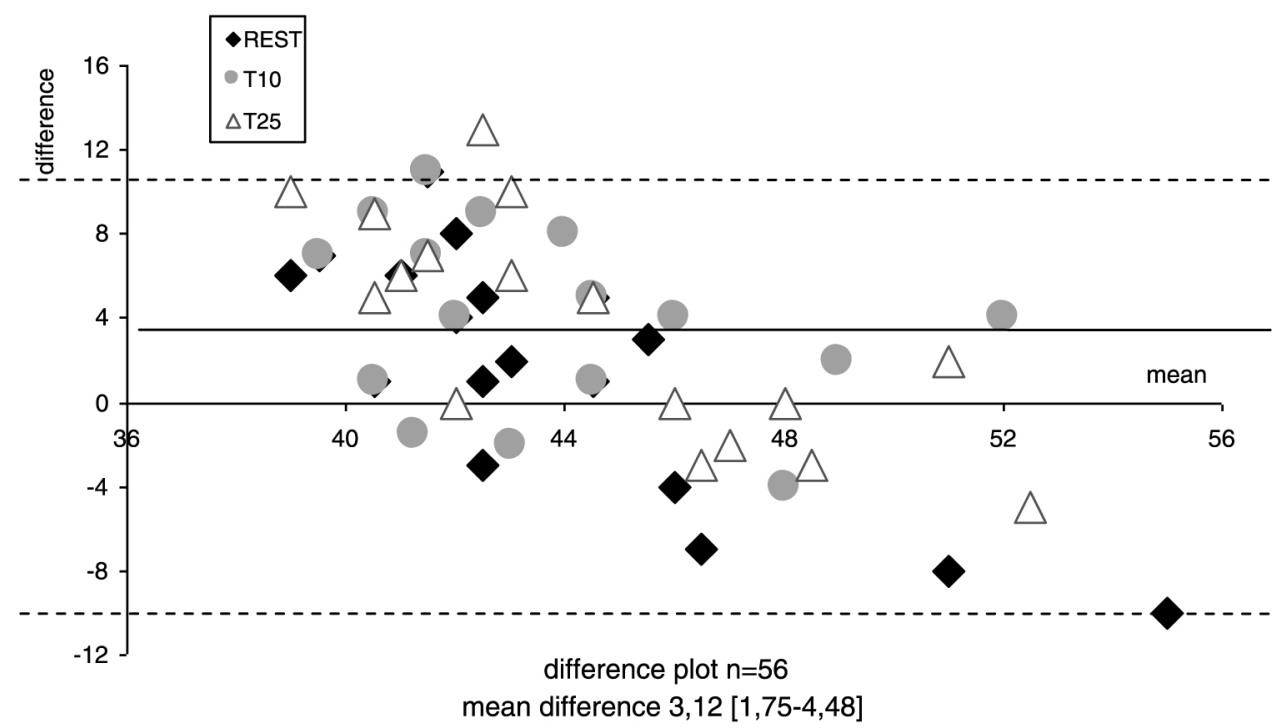

Fig. 2. Upper pannel: Correlation between optimal hematocrit predicted with the model and the actual hematocrit. Lower pannel: Bland-Altman plot showing the agreement between optimal hematocrit predicted with the model and the actual hematocrit. On the average actual hematocrit is slightly higher than the predicted optimal hematocrit.

Correlations among the various viscosity factors and $\mathrm{VO}_{2 \max }$ were looked for, and the only one which appeared significant in this sample was the correlation with het (see Fig. 5). $\mathrm{VO}_{2 \max }$ was negatively correlated with native but not optimal het and was positively correlated with the discrepancy between them. This means that in the less fit subjects het is higher than optimal and in the fitter ones this difference vanishes with some values of actual het slightly lower than optimal.

Figure 6 shows the correlations between the discrepancy (theoretical vs actual het during exercise) and the het response to exercise. Both the maximal value during exercise and the maximal rise in hot during exercise are correlated to this discrepancy. This means that when actual het is higher than optimal, it predicts also a greater increase in hct during exercise and a higher het during exercise. 

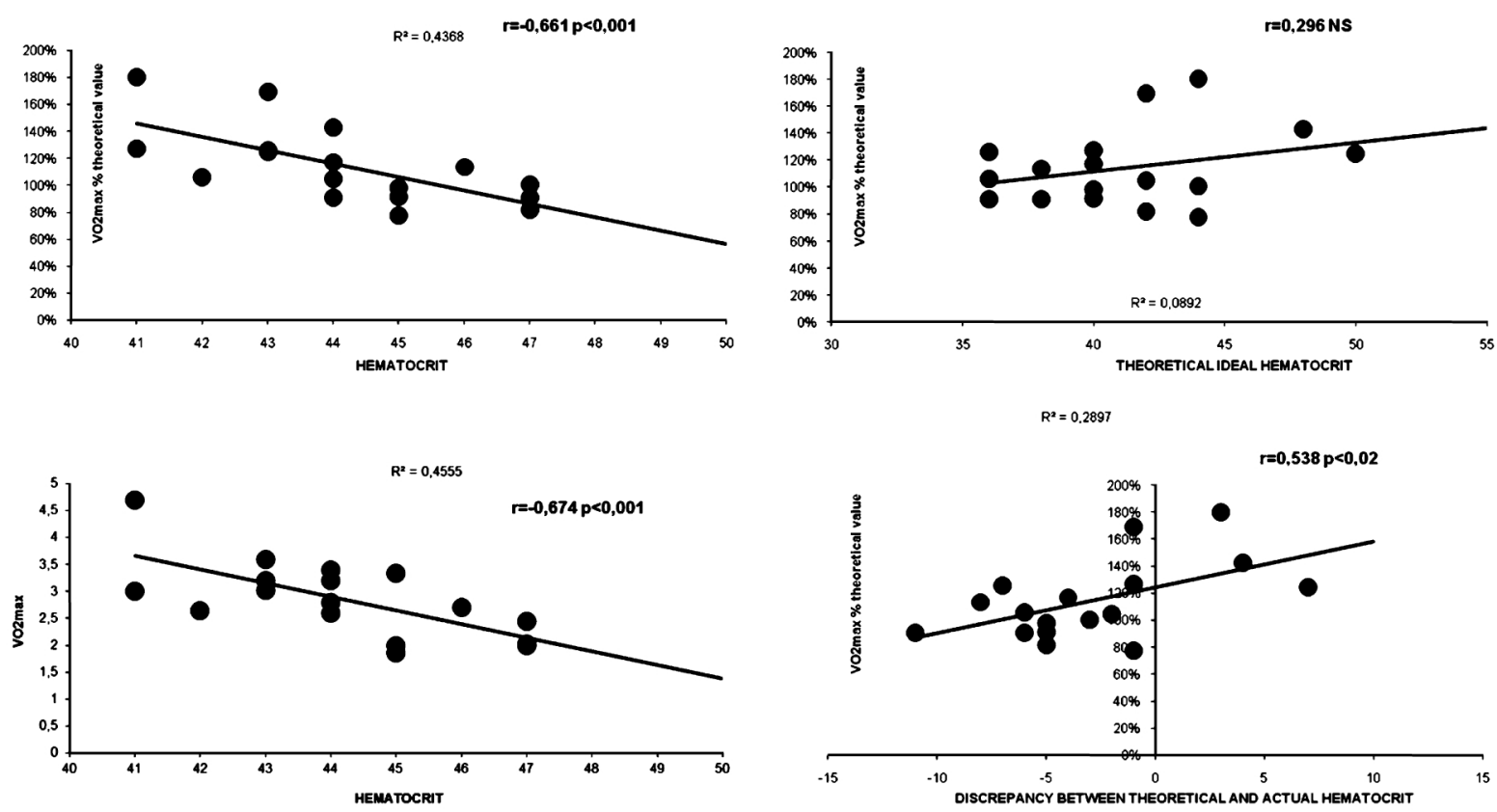

Fig. 5. Correlations between $\mathrm{VO}_{2 \max }$ and hematocrit, showing that aerobic capacity is negatively correlated to actual but not theoretical hematocrit and that the discrepancy between actual and optimal is correlated to aerobic capacity, i.e. in the less fit subjects hematocrit is higher than optimal and in the fitter ones this difference vanishes with some values of actual hematocrit slightly lower than optimal. Discrepancy is presented as optimal minus actual hematocrit, i.e. the more it is negative the more actual is higher than optimal.

There was also a negative correlation between changes in plasma viscosity and changes in RBC rigidity at exercise at T10 $(r=-0.566, p<0.02)$ and at T25 $(r=-0.495, p<0.01)$.

\section{Discussion}

This study shows that in a sample of athletes the prediction of $h / \eta$ ratio and ideal hot with Quemada's equation yields values well correlated to the actual measured values. However hct exhibits discrepancies with the theoretical "optimal" values and these discrepancies are proportional to exercise-induced hct increase, and lower in the fitter athletes.

The old concept of ideal hct, and its hemorheological definition with the top of the curve of $h / \eta$ ratio is now supported by a large body of experimental and clinical evidence [29].

Experimentally in transgenic mice the relationship between het and $\mathrm{VO}_{2 \max }$ describes a bell-shaped curve parallel to that of $h / \eta[25]$.

In preceding studies we showed that actual het is always lower than the predicted value in either athletes or sedentary subjects, but that the discrepancy is around $13-14 \%$ (i.e. 6-7\% in units of hct) in sedentary subjects and of $1-5 \%$ or less (i.e. $0.5-2 \%$ in units of het) in athletes. Apparently the more the athletes are trained the lower the discrepancy. The same is true for the ratio $h / \eta$ which is closely correlated to its theoretical optimal value (and slightly lower) in fit athletes while in sedentary individuals it is $2-6 \%$ higher. In this sample the same tendency is observed.

There is however a large overlap in values of het and $h / \eta$ among sedentary and trained subjects so that it is difficult on the basis of these measurements to define if an individual is trained or not [16]. By contrast various reports indicate that aerobic training (in contrast to resistance training) is associated with a hemorheological profile that promotes both oxygen transport and delivery [24], and 
above its optimal value and to decrease blood flow. The discrepancy between optimal and actual hct represents this reserve allowing systemic het to increase. In sedentary people this gap between optimal and actual het allows the possibility to increase het by 6-7\% (in units of het). In endurance athletes such as those studied here, physiological adaptations make this systemic hot response less necessary and thus the gap is lower $(0.5-2 \%$ in units of het) allowing systemic hot to be set even closer from the ideal value. This regulation of hct is underlied by a regulation of $h / \eta$ explaining that $h / \eta$ is set more closely to its ideal value as predicted by a hemorheologic model. Presumably, a regulatory loop involving erythropoietin and triggered by both $\mathrm{PO}_{2}$ and viscosity plays a central role in this homeostasis.

Whether the picture is the same in other sports, for example resistance sports, remains to be studied.

\section{Conclusions}

Therefore, on the whole, we show in this study that endurance trained athletes have a value of hct and $\mathrm{h} / \eta$ closer to the optimal value predicted by a hemorheologic model based on Quemada's equation. This is likely to be due to the fact that the gap between theoretical and actual values represents a physiological reserve allowing systemic hct to increase during exercise without trespassing the ideal value, avoiding this het response to impair oxygen delivery to tissues. In endurance-trained athletes this protective reserve seems to be less necessary. Other studies are needed in order to ascertain whether this is a general mechanism or an adaptation which is different among sports.

\section{Acknowledgments}

The authors affirm that they have no disclosure of interest concerning the issue investigated in this paper. This study was presented as oral communication at the 18th conference of the Society for Clinical Hemorheology and Microcirculation (ESCHM), Lisbon, June 5-8, 2016.

\section{References}

[1] P.O. Astrand and I. Ryhming, A nomogram for calculation of aerobic capacity (physical fitness) from pulse rate during sub-maximal work, Journal of Applied Physiology 7(2) (1954), 218-221.

[2] P.O. Astrand, K. Rodahl, H.A. Dahl and S.B. Strømme, Textbook of Work Physiology Physiological Bases of Exercise. Champaign, IL, U.S.: Human Kinetics, 2003, pp. 273.

[3] J.-F. Brun, C. Boegner and C. Fédou, Hyperthyroïdie chez un sportif: Aux frontières du surentrainement, Science et Sports 29(2) (2014), 95-100.

[4] J.-F. Brun, E. Varlet-Marie, P. Connes and I. Aloulou, Hemorheological alterations related to training and overtraining, Biorheology 47(2) (2010), 95-115.

[5] T. Chambers, M. Seymour and A. Grewing, Validating the Âstrand-rhyming submaximal protocol for VO2max prediction in recreationally active individuals, International Journal of Exercise Science Conference Proceedings 11(2) (2014), Article 9.

[6] S. Chien, Present state of blood rheology. In: K. Messmer and H. Schmid-Schonbein (Eds) Hemodilution. Theoretical Basis and Clinical Application, Karger, Basel, 1972, pp. 1-45.

[7] R.E. Cink and T.R. Thomas, Validity of the Astrand-Ryhming nomogram for predicting maximal oxygen intake, Britisch Journal of Sports Medicine 15 (1981), 182-185.

[8] M. Diaw, S. Diop, F.Y.W. Soubaiga, M. Seck, B.F. Faye, M.N. Niang, A. Samb and P. Connes, Blood viscosity is lower in trained than in sedentary sickle cell trait carriers, Clinical Hemorheology and Microcirculation 61(1) (2015), 23-29.

[9] M. Guiraudou, L. Maimoun, J.-M. Dumas, M. Julia, I. Raingeard and J.-F. Brun, Composition corporelle mesurée par impédancemétrie segmentaire (BIAS) et performance de sprint chez les rugbymen/Body composition measured by bioimpedance segmental (BIAS) analysis and sprint performance in rugby players, Science \& Sports $\mathbf{3 0}$ [N $\mathbf{N}^{\circ}$ ] (2015), 298-302. 
[10] M.Y. Jaffrin and H. Morel, Body fluid volumes measurements by impedance: A review of bioimpedance spectroscopy (BIS) and bioimpedance analysis (BIA) methods, Medical Engineering \& Physics 30(10) (2008), 1257-1269.

[11] C.A. Kindig, T.E. Richardson and D.C. Poole, Skeletal muscle capillary hemodynamics from rest to contractions: Implications for oxygen transfer, Journal of Applied Physiology 92(6) (2002), 2513-2520.

[12] P. Legros et le groupe "surentrainement", Le surentraînement: Diagnostic des manifestations psychocomportementales précoces, Science \& Sports 8 (1993), 71-74.

[13] H.H. Lipowsky and S. Kovalcheck, The distribution of blood rheological parameters in the microvasculature of cat mesentery, Circulation Research 43(5) (1978), 738-749.

[14] F. Maso, G. Lac and J.-F. Brun, Analysis and interpretation of SFMS questionnaire for the detection of early signs of overtraining: A multicentric study, Science et Sports 20 (2005), 12-20.

[15] F. Maso, G. Lac, E. Filaire, O. Michaux and A. Robert, Salivary testosterone and cortisol in rugby players: Correlation with psychological overtraining items, British Journal of Sports Medicine 38 (2004), 260-263.

[16] A. Pichon, P. Connes and P. Robach, Effects of acute and chronic hematocrit modulations on blood viscosity in endurance athletes, Clinical Hemorheology and Microcirculation.

[17] D. Quemada, Rheology of concentrated disperse systems. II. A model of non newtonian shear viscosity in steady flows, Rheologyca Acta 17 (1978), 632-642.

[18] E. Raynaud, J.-F. Monnier, J.-F. Brun, M. Solère and A. Orsetti, Biochimie et hormonologie de l'exercice submaximal; standardisation d'un test d'effort chez le sportif, Science \& Sports 12 (1997), 72-74.

[19] L.B. Rowell, H.L. Taylor and Y. Wang, Limitations to prediction of maximal oxygen intake, Journal of Applied Physiology 19 (1964), 919-927.

[20] B.Y. Salazar Vázquez, P. Cabrales, A.G. Tsai, P.C. Johnson and M. Intaglietta, Lowering of blood pressure by increasing hematocrit with non-nitric oxide-scavenging red blood cells, American Journal of Respiratory Cell and Molecular Biology 38(2) (2008), 135-142.

[21] B.Y. Salazar Vázquez, J. Martini, A.G. Tsai, P.C. Johnson, P. Cabrales and M. Intaglietta, The variability of blood pressure due to small changes of hematocrit, American Journal of Physiology Heart and Circulatory Physiology 299(3) (2010), H863-H867.

[22] B. Sandor, A. Nagy, A. Toth, M. Rabai and B. Mezey, Effects of moderate aerobic exercise training on hemorheological and laboratory parameters in ischemic heart disease patients, PLoS One 9(10) (2014), e110751.

[23] H. Schmid-Schönbein, E. Volger and H.J. Klose, Microrheology and light transmission of blood III: The velocity of red cell aggregate formation, Pflugers Archiv European Journal of Physiology 254 (1975), 299-317.

[24] M.M. Smith, A.R. Lucas, R.L. Hamlin, L. Robert and S.T. Devor, Associations among hemorheological factors and maximal oxygen consumption. Is there a role for blood viscosity in explaining athletic performance? Clinical Hemorheology and Microcirculation 60(4) (2015), 347-362.

[25] B. Schuler, M. Arras, S. Keller, A. Rettich, C. Lundby, J. Vogel and M. Gassmann, Optimal hematocrit for maximal exercise performance in acute and chronic erythropoietin-treated mice, Proceedings of the National Academy of Sciences USA 107(1) (2010), 419-423.

[26] H. Stark and S. Schuster, Comparison of various approaches to calculating the optimal hematocrit in vertebrate, Journal of Applied Physiology 113(3) (2012), 355-367.

[27] J.F. Stoltz and M. Donner, New trends in clinical hemorheology: An introduction to the concept of the hemorheological profile, Schweizerische medizinische Wochenschrift (Suppl 43) (1991), 41-49.

[28] A. Toth, J. Papp, M. Rabai, P. Kenyeres, Z. Marton, G. Kesmarky, I. Juricskay, H.J. Meiselman and K. Toth, The role of hemorheological factors in cardiovascular medicine, Clinical Hemorheology and Microcirculation 56(3) (2014), 197-204.

[29] X. Waltz, M-D Hardy-Dessources, N. Lemonne, D. Mougenel, M-L Lalanne-Mistrih, Y. Lamarre, V. Tarer, B. Tressières, M. Etienne-Julan, O. Hue and P. Connes, Is there a relationship between the hematocrit-to-viscosity ratio and microvascular oxygenation in brain and muscle? Clinical Hemorheology and Microcirculation 2 (2015), 37-43.

[30] L. Winkler, P. Thoreux and F.J. Lhuissier, Lien entre le score de fatigue de l'enfant sportif et la présence de blessures en section sportive scolaire, Science \& Sports (2016). in press. 